\title{
Estimulando o Pensamento Computacional: uma experiência com ScratchJr
}

\section{Carina Machado de Farias ${ }^{1}$, Valéria Gabriel da Cruz, Jucimária Santos Farias, Daniel Costa Braz, Bárbara Maia Brito, Angela de Souza Carvalho}

Instituto Federal de Educação Ciência e Tecnologia da Bahia- Campus Jacobina Av. Centenário, 500, Nazaré - Jacobina - Bahia, 44.700-000, Brasil

${ }^{1}$ Pesquisadora do JaComp - Grupo de Pesquisa em Computação de Jacobina carina.farias@ifba.edu.br, \{valleriahgabriel, jusfarias1234, jcostabrazbrz, barbarmbrito14\} @gmail.com, angela.s.carvalho@hotmail.com

\begin{abstract}
Computational Thinking has been considered one of the pillars of human intellect, compared to reading, writing and arithmetic, since it can be used to understand, describe, explain and model problems. This paper describes the extension project "Scratch Day - a day to learn joking", carried out with eight to eleven year old students from two municipal public schools in Jacobina, Bahia. The objective of the project was to stimulate logical reasoning and computational thinking by introducing early programming concepts, making use of the ScratchJr tool and the concepts of Computer Science Unplugged and Storytelling.

Resumo. O Pensamento Computacional tem sido considerado um dos pilares do intelecto humano, comparado à leitura, escrita e aritmética, uma vez que pode ser utilizado para compreender, descrever, explicar e modelar problemas. Este trabalho descreve o projeto de extensão "Scratch Day - um dia para aprender brincando", realizado com crianças de oito a onze anos de duas escolas públicas municipais do município de Jacobina, Bahia. O objetivo do projeto foi estimular o raciocínio lógico e o pensamento computacional através da introdução de conceitos iniciais de programação, fazendo uso da ferramenta ScratchJr e dos conceitos de Computação Desplugada e Storytelling.
\end{abstract}

\section{Introdução}

Desde 2006, quando Jeannette Wing comparou o pensamento computacional às habilidades básicas de leitura, escrita e aritmética, teve início um debate internacional sobre a natureza do pensamento computacional e seu valor para a academia, educação e indústria. Para Wing (2006) o pensamento computacional (PC) engloba a habilidade de utilizar conceitos e técnicas da Ciência da Computação na resolução de problemas do cotidiano e nas mais diversas áreas do conhecimento.

Segundo Blikstein (2008), o pensamento computacional não se fundamenta em saber navegar na Internet, acessar e-mails, editar um texto, utilizar planilhas eletrônicas, elaborar uma apresentação ou manipular um equipamento eletrônico. Sua importância está para o processo de resolução de problemas lógicos nos diversos contextos da sociedade, permitindo que se possa aplicar a Computação nas suas ações cotidianas. Trata-se do uso do computador como um instrumento de ampliação do poder cognitivo e 
VIII Congresso Brasileiro de Informática na Educação (CBIE 2019)

Anais do XXV Workshop de Informática na Escola (WIE 2019)

operacional do ser humano, possibilitando aumentar produtividade, inventividade e criatividade.

Empresas multinacionais como Microsoft, Google e Facebook, assim como universidades renomadas, como a Carnegie Mellon, apoiam a proposta do PC e se empenham na disseminação da sua metodologia e na inclusão desse conteúdo no ensino primário e secundário nos Estados Unidos (ANDRADE et al, 2013). França e Tedesco (2015), acreditam que a inserção do Pensamento Computacional deve acontecer desde a educação básica, como forma de melhorar o aprendizado lógico, a capacidade de dedução e conclusão de problemas em nível escolar dos alunos e possibilitar o uso mais eficaz das tecnologias móveis em benefício da sociedade.

Na educação básica, é possível perceber algumas abordagens para a promoção do pensamento computacional, em especial a utilização da ferramenta Scratch $^{1}$, que apresenta um ambiente de programação visual intuitivo para crianças, visto que utiliza elementos já explorados no ambiente escolar como, blocos de encaixe e uso de cores para distinguir conjuntos de comandos. Além do Scratch, outras abordagens como gamificação, computação desplugada ${ }^{2}$, storytelling e robótica educacional têm sido amplamente utilizadas na introdução do pensamento computacional no ensino médio e fundamental (BRACKMANN, 2017).

Considerando a importância da introdução do pensamento computacional ainda na infância, foi desenvolvido o projeto "Scratch Day: um dia para aprender brincando", uma iniciativa extensionista promovida por professores e estudantes de Informática do Instituto Federal da Bahia, campus Jacobina, no ano de 2018. O projeto, cujo objetivo foi estimular e desenvolver o raciocínio lógico e o pensamento computacional, beneficiou 55 crianças, acompanhadas por seus familiares, na faixa etária entre oito e onze anos, da rede pública de ensino fundamental do município, por meio da execução de um evento onde foram realizadas atividades lúdicas, apoiadas nos conceitos de computação desplugada e storytelling e utilizando a ferramenta $\mathrm{ScratchJr}^{3}$. Este trabalho relata a experiência de planejamento e condução do projeto de extensão e apresenta as principais potencialidades e dificuldades experienciadas pelas crianças durante a execução do mesmo.

\section{Abordagens utilizadas para promoção do Pensamento Computacional}

Para Brackmann (2017), o Pensamento Computacional envolve identificar um problema complexo e decompô-lo em partes menores, mais fáceis de serem resolvidas, onde cada parte deve ser analisada, focando nos detalhes importantes e ignorando informações irrelevantes, buscando reconhecer problemas parecidos que já foram solucionados antes, para, por fim, definir uma sequência de atividades ou etapas para resolver cada uma das partes identificadas do problema.

Dentre as abordagens mais utilizadas na promoção do pensamento computacional encontra-se a computação desplugada, que possibilita a aprendizagem de conceitos básicos da Computação através de atividades que dispensam o uso de hardware e software. Essa metodologia promove o desenvolvimento do raciocínio lógico dos alunos, estimula a resolução de problemas e a criatividade em um contexto significativo, através de jogos ou brincadeiras (BELL et al, 2011).

\footnotetext{
${ }^{1}$ https://scratch.mit.edu/

2 https://csunplugged.org/en/

${ }^{3}$ https://www.scratchjr.org/
} 
VIII Congresso Brasileiro de Informática na Educação (CBIE 2019)

Anais do XXV Workshop de Informática na Escola (WIE 2019)

Outra estratégia comumente utilizada para estimular o pensamento computacional é a storytelling, que busca promover a aprendizagem de determinados conteúdos por meio da narração de histórias. Quando adequadamente utilizada, a storytelling amplia o envolvimento do aluno a partir da história contada, tornando o conteúdo abordado mais interessante, além de estreitar a comunicação com os alunos e aumentar as possibilidades de um aprendizado mais efetivo (PALACIOS E TERENZZO, 2018).

Ferramentas de programação em bloco são também boas alternativas para se desenvolver o pensamento computacional em crianças e jovens. Destaca-se nesta categoria, a ferramenta Scratch, para utilização por jovens e adultos. Já para as crianças, evidencia-se o ScratchJr, que foi elaborada a partir da reelaboração da interface gráfica e da linguagem de programação do Scratch para que estes se tornassem mais adequados ao uso do seu público-alvo, ou seja crianças entre cinco e dez anos. O ScratchJr, disponível para uso apenas em tablets, tem por objetivo iniciar as crianças ao pensamento computacional, tendo em vista que com a expansão dos recursos tecnológicos informacionais, a programação tornou-se tão essencial quanto componentes curriculares básicos, a exemplo do domínio da leitura e escrita. Neste aplicativo é possível criar jogos, histórias interativas, animações com personagens e cenários já existentes na ferramenta, ou criados/adaptados pelo usuário. Diante disso, tem-se um estímulo à criatividade e imaginação da criança. $\mathrm{O}$ caráter lúdico do aplicativo, provoca um ensinamento por meio da diversão, tornando o aprendizado da criança mais fácil.

\section{Metodologia de Execução}

Este trabalho se apoiou no método de pesquisa exploratória, sendo realizado através de estudos de caso, onde se buscou observar as potencialidades e dificuldades da utilização do ScratchJr para estimular o pensamento computacional em crianças na faixa etária de oito a onze anos.

Com uma equipe composta por duas professoras e quatro estudantes do Instituto Federal da Bahia, campus Jacobina, dois do Curso Superior de Licenciatura em Computação, e dois do Curso Técnico Integrado em Informática, todos voluntários, o projeto teve início em julho de 2018 e foi finalizado em novembro do mesmo ano, contemplando três etapas na sua execução: formação e planejamento, onde foi realizada uma revisão bibliográfica sobre o tema central e sobre os conteúdos adjacentes, além do planejamento das atividades a serem executadas; execução e coleta de dados, onde as atividades planejadas foram colocadas em prática e os resultados observados foram registrados, e, por fim, análise dos dados, onde os resultados registrados foram analisados e sintetizados.

A fim de aparelhar a equipe com os conhecimentos sobre pensamento computacional, storytelling, computação desplugada e ScratchJr, necessários para o planejamento das atividades a serem executadas nas escolas com as crianças e seus responsáveis, foi realizada uma revisão acerca destes conteúdos, onde a bibliografia relevante da área foi identificada e distribuída entre os participantes do projeto, devendo cada membro da equipe se apropriar dos conceitos abordados e apresentar aos demais, na forma de workshops.

Durante o planejamento foi definido o protocolo de execução do "Scratch Day: um dia para aprender brincando", um evento contemplando atividades lúdicas, apoiadas nos conceitos de computação desplugada e storytelling e utilizando a ferramenta 
VIII Congresso Brasileiro de Informática na Educação (CBIE 2019)

Anais do XXV Workshop de Informática na Escola (WIE 2019)

ScratchJr, com o objetivo de promover o pensamento computacional.

O protocolo aqui apresentado é uma adaptação do protocolo proposto por Santana et al (2017), e buscou explorar os comandos do ScratchJr com mais profundidade, além de inserir atividades de computação desplugada muito citadas em Bocconi et al. (2016) como elementos de suma importância na aprendizagem do pensamento computacional enquanto competência vital para os alunos do ensino fundamental.

\subsection{Protocolo de Execução}

Considerando a realidade local, onde as crianças têm pouco acesso à tecnologia, o protocolo aqui proposto tem duração de 240 minutos, distribuídos em dois encontros de 120 minutos.

São previstas cinco etapas distribuídas em dois dias, devendo acontecer no primeiro dia as etapas de acolhimento, instrução e aplicação, e no segundo dia as etapas de criação e partilha. As atividades previstas em cada etapa são descritas no Quadro 01.

Quadro 1. Descrição das Etapas do Scratch Day

\begin{tabular}{|c|c|c|}
\hline Dia & Etapa & Atividades \\
\hline \multirow{3}{*}{ : } & $\begin{array}{l}01-\text { Acolhimento } \\
(20 \text { minutos })\end{array}$ & $\begin{array}{l}\text { Apresentação da equipe do projeto } \\
\text { Apresentação das crianças e dos responsáveis } \\
\text { Distribuição dos crachás (apenas para as crianças) } \\
\text { Distribuição dos tablets (apenas para os responsáveis) } \\
\begin{array}{l}\text { Distribuição do material de apoio (apenas para os } \\
\text { responsáveis) }\end{array}\end{array}$ \\
\hline & $\begin{array}{l}02 \text { - Instrução } \\
(30 \text { minutos })\end{array}$ & $\begin{array}{l}\text { Realização da dinâmica do robô, para entendimento do } \\
\text { conceito de comando (apenas com as crianças) } \\
\text { Apresentação dos blocos de comandos do ScratchJr }\end{array}$ \\
\hline & $\begin{array}{l}03 \text { - Aplicação } \\
\text { (70 minutos) }\end{array}$ & $\begin{array}{l}\text { Realização de atividades orientadas no ScratchJr usando o } \\
\text { tablete }\end{array}$ \\
\hline \multirow[t]{2}{*}{ 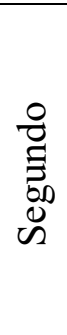 } & $\begin{array}{l}04-\text { Criação } \\
\text { (100 minutos) }\end{array}$ & $\begin{array}{l}\text { Narração da fábula "O pássaro que enganou o gato" pela } \\
\text { equipe } \\
\text { Representação livre da fábula usando o ScratchJr pela } \\
\text { família } \\
\text { Verificação do desempenho das crianças pela equipe }\end{array}$ \\
\hline & $\begin{array}{l}05-\text { Partilha } \\
(20 \text { minutos) }\end{array}$ & Apresentação da história criada pela família para a turma \\
\hline
\end{tabular}

\subsection{Materiais Necessários}

Para a execução do protocolo é necessário disponibilizar duas salas, equipadas com projetores, com capacidade para acomodar as crianças e os familiars separadamente. Em cada sala, é necessário ter cadeiras e mesas, em número compatível com a quantidade de participantes.

São necessários também tablets, preferencialmente um para cada criança e familiar, com sistema operacional Android ou iOS. O ScratchJr deve estar previamente instalado em todos os tablets. 
VIII Congresso Brasileiro de Informática na Educação (CBIE 2019)

Anais do XXV Workshop de Informática na Escola (WIE 2019)

\section{Execução do Evento e Coleta de Dados}

A execução do evento aconteceu mediante contato prévio com a direção das escolas, sugeridas pelos próprios membros da equipe do projeto, onde foram apresentados os objetivos e a metodologia da proposta. Uma vez que as escolas aceitaram participar do projeto, foram acordadas as datas de realização do evento e as turmas que participariam, de acordo com a faixa etária definida para o público-alvo. As famílias foram então convidadas a participar do evento junto com as crianças e, nas datas previstas, o protocolo planejado foi colocado em prática.

\subsection{Perfil dos Participantes}

Duas escolas aceitaram participar do projeto: Escola 01: Escola Municipal Beatriz Guerreiro Moreira de Freitas e Escola 02: Escola Municipal Almir Lopes de Souza, ambas escolas de nível fundamental da rede pública de ensino da cidade Jacobina, Bahia. A Escola 01 situa-se na área urbana e a Escola 02 está localizada na zona rural da cidade.

Para os alunos da Escola 01, o evento, ocorreu na própria escola, no mesmo turno da aula. Já na Escola 02, foi realizado no campus do IFBA, também, no mesmo turno da aula, sendo o transporte dos alunos e familiares fornecidos pela prefeitura da cidade. Em todas as turmas, as crianças foram acompanhadas pelo (a) professor (a) da turma durante a execução do evento.

No total, participaram do evento 55 crianças, 37 da Escola 01 e 18 da Escola 02. A faixa etária das crianças estava entre oito e onze anos, prevalecendo as crianças com nove anos, sendo 15 crianças de oito anos, 19 com nove anos, $13 \mathrm{com}$ dez anos e $08 \mathrm{com}$ onze anos. Dentre os alunos, haviam 32 meninas e 23 meninos, predominando indivíduos do sexo feminino. A maior parte dos alunos estava no quarto ano do ensino fundamental, representando $40 \%$ do total, ou seja, 22 crianças. 18 alunos eram do quinto ano, e 15 do terceiro ano.

Considerando-se as famílias, apenas dezoito acompanharam seus filhos no projeto, observando-se baixa adesão das famílias ao projeto na Escola 01. Dentre os que participaram, 83,3\% dos familiares que acompanharam as crianças eram mães e 94,4\% afirmaram que já haviam utilizado um dispositivo do tipo touch screen, um aspecto positivo para o projeto, uma vez que facilitaria o uso do tablet.

\subsection{Realização das Atividades}

No primeiro dia as crianças foram separadas dos responsáveis, formando dois grupos distintos, ocupando espaços físicos diferentes. Nesse momento, a equipe do projeto foi também dividida, ficando uma professora e dois estudantes responsáveis por conduzir o evento com as crianças e os demais membros responsáveis pelos familiares.

No grupo das crianças, durante a etapa de acolhimento, os membros da equipe se apresentaram e pediram que as crianças também se apresentassem. Nesse momento, as crianças receberam um crachá, com a imagem do gatinho do ScratchJr, onde elas registraram seus nomes. Esse primeiro contato teve por objetivo criar intimidade entre a criança e o personagem principal do aplicativo. Em seguida, na etapa de instrução, as crianças foram convidadas a participar da dinâmica do robô, uma atividade de computação desplugada onde se buscou trabalhar os conceitos de comando e execução. 
VIII Congresso Brasileiro de Informática na Educação (CBIE 2019)

Anais do XXV Workshop de Informática na Escola (WIE 2019)

A dinâmica do robô consiste em dividir a turma em pares, nos quais um componente deve dar instruções claras e objetivas, realizando assim, uma alusão aos comandos do ScratchJr, como: "Dê dois passos para a frente", "Gire à esquerda", enquanto o outro executa estas instruções para chegar a um objetivo, que podem ser balas, pirulitos ou chocolates. Caso as instruções não sejam claras ou todos falem ao mesmo tempo, a criança deve permanecer parada. Quando a criança conseguir pegar o prêmio, deve trocar de papel com o colega, ou seja, passar de robô para dar os comandos.

Após a realização da dinâmica, os tablets, com o ScratchJr previamente instalado, foram entregues às crianças e o aplicativo foi apresentado através da exposição de exemplos, usando slides. Ainda nesse momento, as crianças puderam explorar livremente o aplicativo, inserindo cenários e personagens, e utilizando os blocos de comandos apresentados para programar as ações dos personagens nos cenários.

Para finalizar o primeiro dia, durante a etapa de aplicação, as crianças foram estimuladas a colocar em prática os comandos aprendidos, através da criação dos projetos: Fundo do $\mathrm{Mar}^{4}$, Estações do Ano ${ }^{5}$ e Diálogo ${ }^{6}$. Durante esta prática, a equipe informava qual comando deveria ser utilizado em cada momento e a criança teria que identificar o comando no aplicativo e encaixá-lo na área de programação para executar corretamente a atividade. Diversos comandos foram explorados nessa atividade, tais como os comandos de eventos, movimentos, finalização, aparência, entre outros.

Em paralelo, o grupo dos familiares foi acompanhado por outros componentes da equipe do projeto. Neste outro grupo, durante o acolhimento, a equipe e os familiares se apresentaram e os familiares receberam os tablets e um manual ${ }^{7}$ contendo a descrição dos comandos disponíveis no ScratchJr. Durante a etapa de instrução, de maneira sucinta, por meio de slides, foi explicado aos familiares como funciona a ferramenta e como utilizála. Por fim, durante a aplicação, os familiares realizaram as mesmas atividades propostas para as crianças (Fundo do Mar, Estações do Ano e Diálogo), a fim de colocar em prática os comandos apresentados, e para que, dessa forma, no segundo dia, eles pudessem auxiliar as crianças na execução do projeto final.

No segundo dia, quando foram realizadas as duas últimas etapas, crianças e familiares se reuniram no mesmo espaço físico para realizar a tarefa final. Os crachás e os tablets foram novamente entregues às crianças e os manuais de instruções distribuídos para os responsáveis. Na etapa de criação um dos membros da equipe fez a narração da fábula "O pássaro que enganou o gato" 8 as crianças foram desafiadas a recriar livremente a história, segundo a sua própria interpretação, usando o ScratchJr, podendo receber auxílio de seu acompanhante. Nessa etapa foram explorados os conhecimentos adquiridos no primeiro dia, a capacidade lógica, cognitiva e criativa das crianças. A etapa teve ainda por objetivo reforçar a relação afetiva entre a criança e seu respectivo responsável, buscando uma maior integração familiar na aprendizagem. Após o encerramento da tarefa final deu-se início à etapa de partilha, onde as crianças foram convidadas a apresentar a sua história com o seu responsável e explicar para a turma os comandos que ela conseguiu utilizar.

\footnotetext{
${ }^{4}$ http://tiny.cc/fmv08y

${ }_{6}^{5} \mathrm{http} / / /$ tiny.cc/7mv08y

${ }^{6} \mathrm{http} / / /$ tiny.cc/snv08y

${ }^{7} \mathrm{http}: / /$ tiny.cc/jyv08y

${ }^{8} \mathrm{http}: / /$ tiny.cc/mew08y
} 
É importante ressaltar que na Escola 01 foi necessário adaptar as atividades planejadas devido à baixa adesão dos pais e/ou responsáveis. Dessa forma, as duplas que seriam formadas por responsáveis e crianças, foram formadas entre as crianças e estas se ajudaram na realização do segundo ciclo de atividades, recorrendo à ajuda dos mediadores do projeto, quando necessário. Na Escola 02 foi mantido o planejamento original, uma vez que houve adesão significativa dos responsáveis.

\subsection{Coleta dos Dados}

Foram utilizados dois instrumentos de coleta de dados: uma planilha de verificação", utilizada para registrar informações relevantes acerca do desempenho das crianças durante a execução da atividade final, e um questionário ${ }^{10}$, respondido pelos familiares, que buscou conhecer as impressões das famílias acerca do projeto realizado.

Para registrar as informações sobre o desempenho das crianças de forma efetiva, a equipe foi dividida, ficando cada membro responsável pela observação de, no máximo, quatro crianças. Buscou-se observar quais atividades foram realizadas pelas crianças, com ou sem ajuda do responsável ou do facilitador, e quais atividades deixaram de ser realizadas. Observou-se ainda os aspectos emocionais apresentados pelas crianças durante a execução da tarefa.

\subsection{Resultados Observados}

Para verificar os resultados obtidos com o projeto, a equipe se valeu das observações realizadas durante a execução do evento e das análises das planilhas de verificação e dos questionários de avaliação dos pais.

A partir das observações realizadas durante o evento, considera-se que os resultados obtidos, de uma maneira geral, foram satisfatórios, já que, os alunos participantes conseguiram desempenhar a maioria dos comandos sem ajuda, mesmo a maior parte não possuindo acesso direto e contínuo a aparelhos eletrônicos.

No primeiro dia, durante a etapa de aplicação, após a apresentação dos comandos do ScratchJr, observou-se que tanto responsáveis quanto crianças apresentaram dúvidas no momento de pôr em prática os comandos aprendidos e realizaram com maior facilidade as atividades com comandos mais simples, como os blocos de movimentos, tendo maior dificuldade especialmente em trabalhar com os blocos de evento e de controle. Uma outra observação foi que tanto as crianças quanto os responsáveis tiveram certa dificuldade em entender o conceito do bloco de repetição, em como utilizá-lo e a maneira como encaixar outros comandos neste bloco.

No segundo dia foi possível notar que os alunos que tiveram acompanhamento dos responsáveis realizaram com maior facilidade a atividade proposta, se sentindo mais seguros, possivelmente devido à integração com a família. Já na Escola 01, com a baixa adesão das famílias, as crianças realizaram a atividade sem o apoio familiar e demonstraram maior sentimento de cumplicidade, visto que uns ajudavam aos outros quando não conseguiam realizar determinado comando.

Nas duas escolas, ficou evidente o interesse, a curiosidade e a euforia das crianças com o uso do ScratchJr no tablet. Muitos experimentaram comandos e funcionalidades

\footnotetext{
${ }^{9} \mathrm{http}: / /$ tiny.cc/ghw08y

${ }^{10} \mathrm{http}: / /$ tiny.cc/1jw08y
} 
VIII Congresso Brasileiro de Informática na Educação (CBIE 2019)

Anais do XXV Workshop de Informática na Escola (WIE 2019)

além daqueles que foram ensinados durante o evento, demonstrando desenvoltura na utilização da ferramenta e apresentando facilidade de aprendizagem em seu uso.

Além da observação in loco, as planilhas de verificação, cujos registros foram feitos durante a execução do evento nas escolas, também trouxe informações relevantes acerca dos resultados alcançados. A Tabela 1 apresenta os números extraídos das planilhas de verificação e o Gráfico 1 expressa visualmente esses dados numéricos.

Tabela 1. Números das planilhas de verificação

\begin{tabular}{|l|c|c|c|}
\hline Item Observado & Realiza sem ajuda & Realiza com ajuda & Não realiza \\
\hline Criar projeto & 45 & 10 & 0 \\
\hline Inserir cenário & 43 & 12 & 0 \\
\hline Inserir personagem & 44 & 11 & 0 \\
\hline Usar um ou mais blocos de movimentos & 46 & 9 & 0 \\
\hline Iniciar com a bandeira verde & 41 & 14 & 0 \\
\hline Enviar mensagem de início & 14 & 27 & 14 \\
\hline Iniciar com mensagem & 16 & 23 & 16 \\
\hline Usar um ou mais blocos de aparência & 30 & 18 & 7 \\
\hline Usar um ou mais blocos de controle & 21 & 21 & 13 \\
\hline Usar um ou mais blocos de som & 26 & 20 & 9 \\
\hline
\end{tabular}

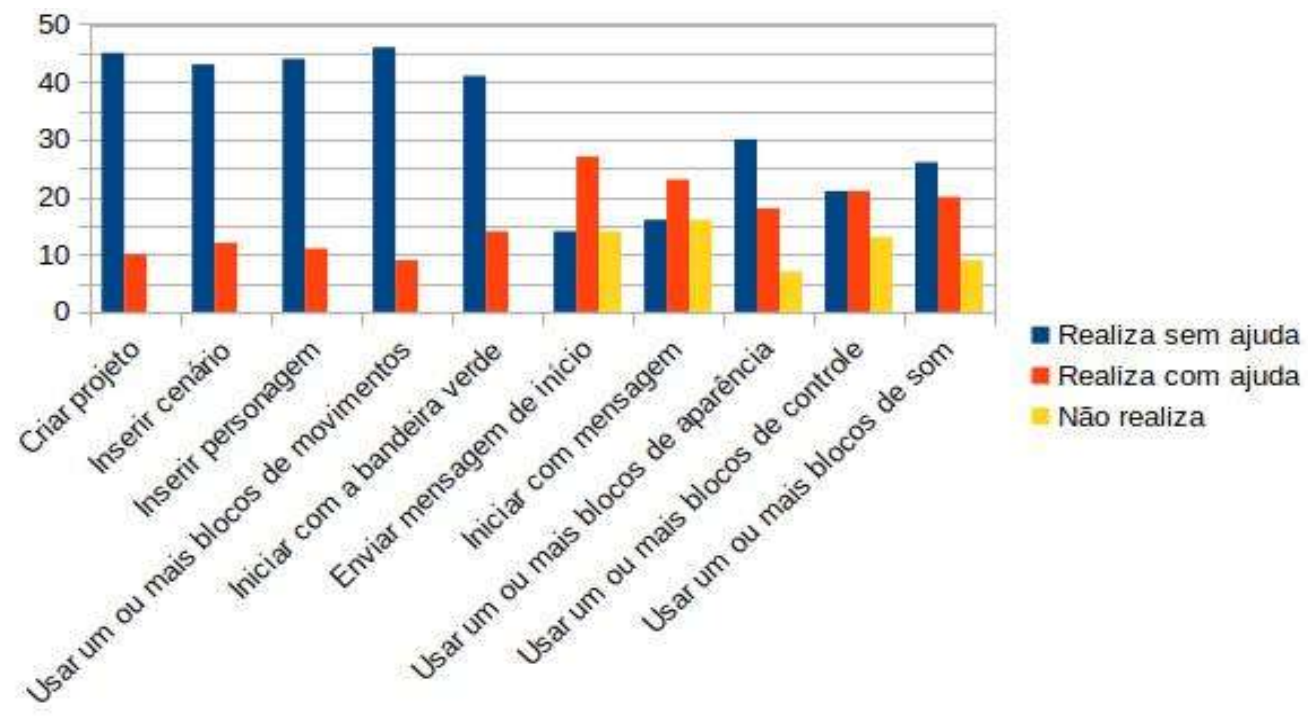

Gráfico 1. Informações compiladas das planilhas de verificação

Ao analisar esses dados, é possível concluir que, as crianças compreenderam satisfatoriamente a interface do aplicativo, uma vez que a maioria conseguiu criar os projetos, inserir cenários e personagens nos projetos, sem ajuda.

É possível perceber também que não houve dificuldades em usar os blocos de movimentos, sendo este o item observado onde a menor quantidade de crianças necessitou de ajuda para utilizar.

Por outro lado, verificou-se que as crianças sentiram maior dificuldade na utilização dos blocos de evento, em especial "enviar mensagem de início" e "iniciar com mensagem", sendo estes os itens observados onde a maior quantidade de crianças não conseguiu realizar, mesmo contando com a ajuda do familiar ou do colega. 
Além das planilhas de verificação, na Escola 02, onde houve a adesão dos pais, foi possível utilizar também o questionário destinado aos responsáveis, como ferramenta de avaliação dos resultados alcançados pelo projeto. Os questionários revelaram que $77,8 \%$ dos responsáveis não tiveram dificuldades em utilizar o aplicativo, o que, mais uma vez, demonstra o quanto intuitivo é a sua interface. $94,4 \%$ dos responsáveis consideraram o projeto divertido e que estimula a criatividade das crianças. A avaliação positiva sobre os efeitos do projeto para o estímulo da aprendizagem se repete quanto à continuidade do uso do ScratchJr, em que apenas um dos responsáveis expressou não ter certeza sobre se continuaria a usar o aplicativo caso possuísse um tablet, havendo $94,4 \%$ de indicação de continuidade de uso caso fosse possível.

Em termos gerais, a opinião dos pais e responsáveis sobre a utilização da tecnologia no dia-a-dia na escola é positiva, com $66,7 \%$ de absoluta aprovação, considerando que em todos os casos a utilização de tecnologia é positiva para a aprendizagem, enquanto em torno de um terço $(33,3 \%)$ considera que apenas às vezes a utilização de tecnologia pode ser benéfica para a aprendizagem. Nenhum participante julgou que a tecnologia atrapalha a aprendizagem das crianças no ambiente escolar.

\section{Considerações Finais e Trabalhos Futuros}

Pensamento computacional é uma das habilidades a serem desenvolvidas pelos estudantes nos dias atuais, entretanto, este é um conteúdo que ainda não está integrado ao currículo escolar brasileiro. Muitos trabalhos estão sendo desenvolvidos, buscando-se formas de trabalhar tal habilidade, mais comumente em atividades de extensão.

Diante deste contexto, este trabalho apresentou o projeto "Scratch Day: um dia para aprender brincando", uma iniciativa extensionista promovida por professoras e estudantes dos cursos de Informática do Instituto Federal da Bahia, campus Jacobina, no ano de 2018. O projeto, teve por objetivo estimular o raciocínio lógico e o pensamento computacional, através da introdução de conceitos iniciais de programação de computadores, usando a linguagem de blocos disponível no aplicativo ScratchJr. Para tornar o aprendizado ainda mais interessante e divertido, foram desenvolvidas também atividades lúdicas apoiadas nos conceitos da computação desplugada e storytelling. Foram beneficiadas 55 crianças, acompanhadas por seus familiares, na faixa etária entre oito e onze anos, alunos de duas escolas da rede pública de ensino fundamental do município.

Os resultados observados durante a execução do projeto são positivos e sugerem que a ferramenta ScratchJr pode ser utilizada para exercitar o pensamento computacional nas crianças, promovendo uma experiência lúdica e motivadora e estimulando a capacidade lógica, cognitiva e criativa das crianças. Como resultados obtidos pode-se destacar ainda:

- Inserção dos estudantes integradores da equipe do projeto na prática extensionista e da pesquisa científica;

- Ampliação do conhecimento dos estudantes integradores da equipe do projeto acerca do pensamento computacional, computação desplugada, ScratchJr e storytelling; 
VIII Congresso Brasileiro de Informática na Educação (CBIE 2019)

Anais do XXV Workshop de Informática na Escola (WIE 2019)

- Estímulo do raciocínio lógico, criatividade, autonomia, capacidade de resolução de problemas e trabalho em equipe, nas crianças beneficiadas pelo projeto;

- Aproximação da escola com as famílias.

Como trabalho futuro pretende-se adaptar o protocolo para uma experiência com maior duração, onde seja possível integrar as atividades propostas aos diversos conteúdos do currículo formal, buscando analisar se o pensamento computacional repercute de alguma forma no rendimento escolar das crianças. Além desse aspecto, deseja-se também analisar o projeto do ponto de vista dos professores das escolas que acompanharam a execução das atividades.

\section{Referências}

Andrade, D.; Carvalho, T.; Silveira, J.; Cavalheiro, S.; Foss, L.; Fleischmann, A.M.; Aguiar, M.; Reiser, R. (2013). Proposta de Atividades para o Desenvolvimento do Pensamento Computacional no Ensino Fundamental. In Anais do Workshop de Informática na Escola (CBIE/WIE 2013) (p. 169). doi: http://dx.doi.org/10.5753/cbie.wie.2013.169.

Bell, T.; Witten, I. H.; Fellows, M. Computer Science Unplugged: Ensinando Ciência da Computação, 2011. Disponível em $<$ http://csunplugged.org/sites/default/files/books/CSUnpluggedTeachers-portuguesebrazil-feb-2011.pdf $>$ Acesso em 16 nov. de 2018.

Blikstein, P. (2008). O pensamento computacional e a reinvenção do computador na educação. Disponível em < http://www.blikstein.com/paulo/documents/online/ol_pensamento_computacional.ht $\mathrm{ml}>$ Acesso em: 20 de nov. de 2018.

Bocconi, S.; Chioccariello, A.; Dettori, J.; Ferrari, A.; Engelhardt, K. (2016). Developing Computational Thinking in Compulsory Education. Disponível em $<$ http://publications.jrc.ec.europa.eu/repository/bitstream/JRC104188/jrc104188_co mputhinkreport.pdf> Acesso em: 19 de nov. de 2018.

Brackmann, C. P. (2017) Desenvolvimento do Pensamento Computacional através de Atividades Desplugadas na Educação Básica. 226 f. Tese (Doutorado) - Programa de Pós-graduação em Informática na Educação, Centro de Estudos Interdisciplinares em Novas Tecnologias na Educação, Universidade Federal do Rio Grande do Sul, Porto Alegre.

França, R. D.; Tedesco, P. (2015). Desafios e oportunidades ao ensino do pensamento computacional na educação básica no Brasil. In Anais dos Workshops do Congresso Brasileiro de Informática na Educação (CBIE/WCBIE 2015) (Vol. 4, p. 1464). doi:10.5753/cbie.wcbie.2015.1464.

Palacios, F; Terenzzo, M. (2018) O guia completo do Storytelling. Alta Books Editora.

Santana, A.L.M.; Raabe, A.L.A.; Metzger, J.P.; Henrique, A.S.; Santana, L.F.M.; Maciel, A. da C.P.; Maciel, C. (2017). Scratch Jr - Brincando em Família: um relato de experiências sobre introdução a programação no ambiente escolar. In Anais do Workshop de Informática na Escola (CBIE/WIE 2017) (p. 432). doi:10.5753/cbie.wie.2017.432.

Wing, J. M. (2006). Computational thinking. Commun. ACM, v.49, n.3, p.33-35. 